\title{
Multisystemic smooth muscle dysfunction syndrome
}

INSERM

\section{Source}

INSERM. (1999). Orphanet: an online rare disease and orphan drug data base.

Multisystemic smooth muscle dysfunction syndrome. ORPHA:404463

Multisystemic smooth muscle dysfunction syndrome is a rare, genetic, vascular disease

characterized by congenital dysfunction of smooth muscle throughout the body,

manifesting with cerebrovascular disease, aortic anomalies, intestinal hypoperistalsis,

hypotonic bladder, and pulmonary hypertension. Congenital mid-dilated pupils non-

reactive to light associated with a large, persistent patent ductus arteriosus are characteristic hallmarks of the disease. 